\section{Bodies without names: A global challenge}

To the Editor: It was with great interest that we read the article 'Bodies without names: A retrospective review of unidentified decedents at Salt River Mortuary, Cape Town, South Africa, 2010 2017' by Reid et al., ${ }^{[1]}$ which gives very informative insight into the work with unknown bodies in one of the busiest mortuaries of the Western Cape.

Identification of unknown bodies is a challenging task that can only be successfully carried out when forensic scientists and investigating authorities are able to work together closely and effectively. If many such cases remain unsolved, the social consequences can become so severe that society loses faith in a functioning rule of law.

This is currently the situation in Mexico. From the beginning of the so-called war on drugs in 2006 to the end of 2019, more than 35000 bodies remained unidentified nationwide. No one knows how many of them may be those of persons who have been reported missing more than 60000 since 2006 .

During the past months, we have worked closely with forensic scientists and authorities to improve the identification process in the state of Jalisco, Mexico. The workload of the Instituto Jaliscience de Ciencias Forenses (IJCF) in Guadalajara, Jalisco, is comparable to that of the Salt River Mortuary, and the problems we face are very similar to those described by Reid et al. ${ }^{[1]}$

On the one hand, all unidentified bodies are routinely examined by a team of forensic pathologists, odontologists and anthropologists, as well as criminalists, and samples for DNA testing are taken to obtain proper postmortem data. On the other hand, however, there is a lack of antemortem data on missing persons: information on dental status is available in few cases, and there is no nationwide DNA database for missing persons in Mexico. Furthermore, the use of antemortem fingerprints, e.g. from driving licences or electoral registers, often fails because of alleged data security problems. The comparison of existing data is therefore anything but efficient.

In Mexico, families often approach forensic institutes directly to search for their missing relatives, without involving investigating authorities. The relatives leave antemortem data on their loved ones at the forensic institutes, hoping for closure. This information mainly consists of descriptions of physical features and individual characteristics.

According to our experience, this information is underutilised even though it has a good chance of speeding up the identification process, especially when features such as tattoos are present. More than $45 \%$ of 2045 complete bodies examined at the IJCF during the first half of 2019 were tattooed, and more than $28 \%$ of all bodies had tattoos on the head, neck or forearms and hands - i.e. body regions that are usually exposed. ${ }^{[2]}$ Information on such visible tattoos could easily be provided by families, or be accessed from pictures in social networks on the internet. Tattoos could and should be used more frequently to establish a suspected identity, to help confirm a presumed identity, or to prioritise subsequent investigations such as DNA testing.

Taking local particularities into account, pragmatic solutions need to be found and used worldwide to enable unknown bodies to be identified reliably and in a reasonable amount of time - as a sign of respect for the deceased, to give closure to families, to maintain trust in the rule of law, and last but not least, to help the forensic service operate with optimal efficiency.

\section{G Birngruber}

Department of Legal Medicine, University Hospital Frankfurt, Goethe University, Frankfurt am Main, Germany

birngruber@med.uni-frankfurt.de

\section{E G Martinez Peña}

Instituto Jaliscience de Ciencias Forenses, Guadalajara, Mexico

\section{F Holz}

Department of Legal Medicine, University Hospital Frankfurt, Goethe University, Frankfurt am Main, Germany

\footnotetext{
1. Reid K, Martin L, Heathfield L. Bodies without names: A retrospective review of unidentified decedents at Salt River Mortuary, Cape Town, South Africa, 2010 - 2017. S Afr Med J 2020;110(3):223226. https://doi.org/10.7196/SAMJ.2020.v110i3.14192

2. Birngruber CG, Peña E, Corrales Blanco L, Holz F. The use of tattoos to identify unknown bodies Rechtsmedizin 2020;30:219-224. https://doi.org/10.1007/s00194-020-00396-y
}

S Afr Med J 2020;110(9):828. https://doi.org/10.7196/SAMJ.2020.v110i9.15034 